\title{
"Prevalence of alcohol-impaired drivers based on random breath tests in a roadside survey"
}

Manuela Alcañiz, Montserrat Guillén, Daniel Sánchez-Moscona, Miguel Santolino, Oscar Llatje and Lluís Ramon 


\section{$\oplus_{\circledast}|| R|E| A \mid$}

Institut de Recerca en Economia Aplicada Regional i Pública Research Institute of Applied Economics

\section{Universitat de Barcelona}

\section{Av. Diagonal, $690 \bullet 08034$ Barcelona}

WEBSITE: www.ub.edu/irea/•CONTACT: irea@ub.edu

The Research Institute of Applied Economics (IREA) in Barcelona was founded in 2005, as a research institute in applied economics. Three consolidated research groups make up the institute: AQR, RISK and GiM, and a large number of members are involved in the Institute. IREA focuses on four priority lines of investigation: (i) the quantitative study of regional and urban economic activity and analysis of regional and local economic policies, (ii) study of public economic activity in markets, particularly in the fields of empirical evaluation of privatization, the regulation and competition in the markets of public services using state of industrial economy, (iii) risk analysis in finance and insurance, and (iv) the development of micro and macro econometrics applied for the analysis of economic activity, particularly for quantitative evaluation of public policies.

IREA Working Papers often represent preliminary work and are circulated to encourage discussion. Citation of such a paper should account for its provisional character. For that reason, IREA Working Papers may not be reproduced or distributed without the written consent of the author. A revised version may be available directly from the author.

Any opinions expressed here are those of the author(s) and not those of IREA. Research published in this series may include views on policy, but the institute itself takes no institutional policy positions. 


\title{
Prevalence of alcohol-impaired drivers based on random breath tests in a roadside survey
}

\author{
Manuela Alcañiz $^{\dagger}$, Montserrat Guillén ${ }^{\dagger}$, Daniel Sánchez-Moscona ${ }^{\dagger}$, \\ Miguel Santolino ${ }^{+*}$, Oscar Llatje ${ }^{\ddagger}$, Lluís Ramon ${ }^{\ddagger}$ \\ † Department of Econometrics, Riskcenter-IREA, University of Barcelona, Spain \\ ${ }^{\ddagger}$ Catalan Traffic Authority, Spain
}

\begin{abstract}
:
Sobriety checkpoints are not usually randomly located by traffic authorities. As such, information provided by non-random alcohol tests cannot be used to infer the characteristics of the general driving population. In this paper a case study is presented in which the prevalence of alcohol-impaired driving is estimated for the general population of drivers. A stratified probabilistic sample was designed to represent vehicles circulating in non-urban areas of Catalonia (Spain), a region characterized by its complex transportation network and dense traffic around the metropolis of Barcelona. Random breath alcohol concentration tests were performed during spring 2012 on 7,596 drivers. The estimated prevalence of alcohol-impaired drivers was $1.29 \%$, which is roughly a third of the rate obtained in non-random tests. Higher rates were found on weekends ( $1.90 \%$ on Saturdays, $4.29 \%$ on Sundays) and especially at night. The rate is higher for men $(1.45 \%)$ than for women $(0.64 \%)$ and the percentage of positive outcomes shows an increasing pattern with age. In vehicles with two occupants, the proportion of alcohol-impaired drivers is estimated at $2.62 \%$, but when the driver was alone the rate drops to $0.84 \%$, which might reflect the socialization of drinking habits. The results are compared with outcomes in previous surveys, showing a decreasing trend in the prevalence of alcohol-impaired drivers over time.
\end{abstract}

\section{Keywords}

Breath alcohol concentration, blood alcohol content, drunk driving, sampling analysis, weights, substance abuse.

\footnotetext{
* Corresponding author: Miguel Santolino (E-mail: msantolino@ub.edu), Tf.: (+34) 934020484 Department of Econometrics, Riskcenter-IREA, University of Barcelona, Av. Diagonal, 690, E-08034 Barcelona, Spain.
} 


\section{Introduction and scope}

Excessive alcohol consumption among drivers results in a significantly increased risk of motor vehicle accidents (WHO, 2011). Moreover, a large body of literature highlights the presence of alcohol and drugs in drivers that have been either severely or fatally injured in traffic accidents (Holmgren et al., 2005; Wagenaar et al., 1995; Ahlm et al., 2009). In response, road safety policies, in which the maximum level of alcohol permitted to drivers has become a key issue, have been devised aimed at reducing alcohol-related traffic accidents worldwide.

Ensuring that these alcohol limits are not exceeded is the responsibility of the police who can set up sobriety checkpoints to control the alcohol consumption of drivers. Such checkpoints are known to act as a deterrent on both the drinking behavior and drug use of drivers (Löbmann, 2002). The authorities are able to identify particularly dangerous locations (near centers selling alcohol, such as clubs and discotheques, for example) and high risk days and time frames, and intensify the number of sobriety checkpoints at such locations, and on such days and hours accordingly. In addition, alcohol tests can be administered when an individual is suspected of driving under the effects of alcohol, or following an accident in which people have been injured. Yet, although data on levels of alcohol concentration provided by non-random alcohol checkpoints or obtained from drivers involved in accidents with victims are a source of valuable information, they cannot be extrapolated to the general driving population as they are generated by a biased information collection process.

Here we present a case study in which the prevalence of alcohol-impaired drivers is estimated for the general population of drivers in Catalonia (Spain) in 2012. This research project was promoted by the Catalan Traffic Authority, which had previously carried out three similar studies in 2007, 2009, and 2010. Our case study comprises a roadside survey implemented during spring 2012 with the collaboration of the regional traffic agents who are responsible for traffic law enforcement, road security and the prevention of traffic accidents in Catalonia. The sample was designed to be representative of Catalonia's driving population, which involved implementing a complex statistical sampling procedure and an equally complex statistical inference process. However, the methodology reported should be of interest for similar studies of general driving populations.

A total of 7,596 breath alcohol tests were performed on randomly selected drivers, being representative of the population of vehicles circulating in non-urban areas. The standard alcohol breath testing procedure was followed to measure alcohol levels. The test estimates the alcohol blood concentration by measuring the amount of alcohol in the air exhaled by the driver. Drivers exceeding the legal limit of 0.25 milligrams of 
alcohol in a liter of breath $(0.25 \mathrm{mg} / \mathrm{l})$ face administrative fines for traffic offenses ${ }^{1}$. Drivers exceeding $0.60 \mathrm{mg} / \mathrm{l}$ of breath alcohol concentration (BrAC) face criminal prosecution.

The aim of this study is to estimate the prevalence of alcohol-impaired drivers in the general population circulating in non-urban areas of Catalonia. The main objectives of the analysis are:

a) to provide an accurate estimate of alcohol concentration in a sample of drivers that is representative of the general population of drivers;

b) to estimate the percentage of alcohol-impaired drivers by road type, day of the week, time of the day and other factors;

c) to compare the estimated percentage of alcohol-impaired drivers in the general population with the estimated percentage of alcohol-impaired drivers according to non-random checkpoints, and

d) to find evidence that the percentage of drivers with a BrAC level above the legal limit presents a decreasing trend when compared to the outcomes of surveys conducted in 2007, 2009, and 2010.

The article is organized as follows. A literature review is undertaken in the next section. In section 3 the methodology used in the design of the sample is explained. The results are reported in section 4 and our conclusions are summarized in section 5 .

\section{Literature review}

Alcohol-impaired driving is the cause of a significant percentage of injuries and fatalities associated with road traffic accidents in most developed countries, where considerable efforts have been invested in seeking to understand the phenomenon and in designing and implementing adequate deterrence policies. As a result, the academic literature examining the issue is very extensive. However, most articles tend to concern themselves with one or more of the following issues: a) studying the driving impairment attributable to alcohol consumption and its interaction with other drugs; b) identifying the percentage number of motorists that drive under the influence of alcohol; c) estimating the percentage number of road traffic accidents associated with excessive (i.e., over the legal limit) alcohol consumption; d) identifying high-risk

\footnotetext{
${ }^{1}$ The general rate is 0.25 milligrams of alcohol in a liter of breath or, its equivalent, 0.5 grams of alcohol per liter of blood. However, the legal threshold is $0.15 \mathrm{mg} / \mathrm{l}$ for professional drivers of special vehicles such as ambulances, public transport vehicles, school buses or vehicles carrying hazardous substances. The latter limit also applies to drivers who have obtained their license less than two years prior to the date of the test.
} 
groups; e) evaluating the effects of different deterrence policies; and f) methodological considerations.

It is widely accepted that alcohol consumption has a broad range of impairing effects on the skills required for driving. Specifically, it leads to a worsening of psychomotor skills, reaction times, the ability to keep a vehicle within traffic lanes, speed control and hazard perception, among others (Moskowitz and Fiorentino, 2000; Downey et al., 2013). Other legal and illegal psychoactive drugs have also been found to impair the ability to drive significantly (Woratanarat et al., 2009). Moreover, two or more psychoactive drugs combined can have a more than additive effect on the deterioration of driving skills (Downey et al., 2013).

As such, there is a broad consensus in the literature regarding the important quantitative effect of drink driving on accident fatalities. For instance, 45,000 casualties and 1,500 deaths can be related to drink driving in Germany each year (Löbmann, 2002). Similarly, according to official statistics for 2001, 8.4\% of all injuries suffered in accidents and $10 \%$ of all fatal road traffic accidents in Belgium were alcohol-related (Vanlaar, 2005). Likewise, 25\% of serious injuries produced in road traffic accidents were related to alcohol in the Netherlands (Mathijssen, 2005). On a more positive note though, most articles report a decreasing trend in the number of alcohol-related road traffic accidents (Peek-Asa, 1999; Vanlaar, 2005; Mathijssen, 2005; Williams, 2006; Vanlaar et al., 2012). For instance, while 57\% of motor vehicle deaths were related to alcohol in the United States in 1982, this percentage had fallen to $40.9 \%$ in 1996 (Peek-Asa, 1999). More recently, a 2007 survey estimated that this figure had fallen to 33\% (Bergen et al., 2011). This trend seems to be present in data for most developed countries, with significant falls in the number of alcohol-related accidents during the 1990s and 2000s.

Although the contribution of excessive alcohol consumption to the number of road traffic accidents is considerable, most studies note that the proportion of motorists who actually drive under the effects of alcohol is relatively small. For instance, $1.80 \%$ of U.S. adults reported episodes in which they have driven drunk (Bergen et al., 2011), while $3.31 \%$ of all drivers in Belgium were estimated in one study to have a blood alcohol content (BAC) level above the legal limit $^{2}$ (Vanlaar, 2005). However, the percentage of alcohol-impaired drivers on the roads seems to be significantly higher at nighttime and, even more so, on weekends. In this study, Vanlaar (2005) estimates that the percentage of alcohol-impaired drivers rises to $7.68 \%$ on weekend nights.

\footnotetext{
${ }^{2}$ Vanlaar (2005) notes that this figure might be negatively biased, given that not all accidents are recorded and the drivers involved in an accident are not always tested for alcohol. However, the magnitude of the bias is thought to be relatively small.
} 
Yet, the percentage of alcohol-impaired drivers has also decreased steadily over time. For example, in the Netherlands, the share of drivers with a BAC above the legal limits fell from $15 \%$ in 1970 to $4.5 \%$ in 2000 . Nevertheless, a surprisingly high proportion of alcohol-impaired drivers present a BAC above $1.3 \mathrm{~g} / \mathrm{l}$, which is almost three times higher than the legal limit in most developed countries, typically around $0.5 \mathrm{~g} / \mathrm{l}$ (Mathijssen, 2005). This remains one of the challenges for future deterrence policy design.

Most studies report that a significantly high proportion of alcohol-impaired drivers are male. In the 2010 U.S. Behavioral Risk Factor Surveillance Survey, as many as $81 \%$ of the respondents that reported episodes of drunk-driving were men (Bergen et al., 2011). In the Netherlands, men aged 18-24 constitute a very high risk group, given that they represent less than $5 \%$ of the country's population but are responsible for almost 25\% of accidents (Mathijssen, 2005). A study performed using data from the 2007 edition of the National Roadside Survey ${ }^{3}$ (NRS) in the U.S. reaches a similar conclusion (Kelley-Baker et al., 2013). In this case, individuals aged 21-24 were 4.5 times more likely to drink-drive than other age groups, while the percentage of positives was significantly higher for men than for women.

There is no conclusive evidence regarding differences in the rate of alcohol-impaired driving across different types of vehicle. For instance, Peek-Asa and Kraus (1996) note that motorcycle drivers exhibit the highest rate of alcohol use amongst all road users. Chongsuvivatwong et al. (1999) arrive at a similar conclusion for the case of Thailand. By contrast, Sun et al. (1998) report a mean BAC level for motorcyclists that is significantly lower than that for drivers of four-wheeled vehicles. They argue that this might be attributed to the fact that riding a motorcycle requires greater coordination and balance. In any case, all of these estimates should be considered with care due to the fact that they are often obtained from samples of individuals who suffered a traffic accident. Thus, they may be subject to a relatively large sample selection bias.

Surprisingly, a study performed among drivers in Brazil between 2005 and 2007 found that individuals who considered drunk driving as a serious social offense were more likely to incur in such behavior than their counterparts. Similarly, individuals who identified themselves as regular alcohol consumers were three times as likely to exceed the legal BAC limit (Campos et al., 2013). Moreover, it should be noted that drink driving seems to be associated with the non-usage of vehicle safety devices such as seat-belts or crash helmets in the case of motorcyclists (Bergen et al., 2011; Woratanarat et al., 2009). Despite this, Voas et al. (2013) found evidence of some precautionary behavior amongst youngsters when leaving a drinking location.

\footnotetext{
${ }^{3}$ The methodology employed in the 2007 U.S. National Roadside Survey to estimate the prevalence of alcohol-impaired driving is explained in Lacey et al. (2011).
} 
Specifically, $20 \%$ of the drivers presented a BAC level above the legal limit compared to $47 \%$ in the case of the passengers. Voas et al. (2013) point out that drivers with a high BAC level switched to passenger status and were replaced by former passengers with lower levels as a means to avoid alcohol-impaired driving.

Many policies have been implemented worldwide in order to reduce the prevalence of alcohol-impaired drivers. These include the introduction of BAC limits, the introduction of random breath testing, increased enforcement levels, the introduction of evidential breath testing, monetary and non-monetary penalties or publicity and educational programs. Of these, in the Netherlands the introduction of BrAC testing checkpoints combined with increased enforcement levels and educational programs seem to be the most effective policies (Mathijssen, 2005). Löbmann (2002) notes that the quality rather than the quantity of sobriety checkpoints serves as a better deterrent, suggesting that fewer yet more efficient checkpoints have a higher deterrence effect than operating a higher number of inefficient controls. On this note, Vanlaar (2005) suggests that alcohol-impaired drivers respond to a higher perceived probability of detection. This explains why drunk drivers tend to avoid high traffic count road sites and keep to roads with lower traffic intensity, where they estimate there is a lower probability of their being caught (Vanlaar, 2008). However, in the meta-analysis conducted by Wagenaar et al. (1995) the authors point out that the number of studies that identify the effects of deterrence policies is very limited due to a lack of data or the application of a poorly developed methodology.

We should stress that very few studies have been able to estimate the percentage of alcohol-impaired drivers in the driving population accurately. This might be due to the fact that in order to gather data for such a study, the cooperation and/or authorization of the corresponding traffic authorities is essential. However, police forces typically only perform strategic sobriety tests on drivers in particularly high-risk time-slots and locations. Thus, it is intrinsically difficult to gather information from a random representative sample. Of the literature reviewed, only the studies conducted by Vanlaar (2005) and Gjerde et al. (2008) are based on samples that are random in time and location to estimate the prevalence of alcohol-impaired drivers in Belgium and Norway, respectively ${ }^{4}$. These studies involved the participation of the traffic authorities who performed the alcohol tests on the drivers. This study follows a similar procedure based on the development of a statistical methodology for designing a random sample of the driving population.

\footnotetext{
${ }^{4}$ The methodology used in the 2007 National Roadside Survey to calculate the proportion of alcoholimpaired drivers in the United States is random in time and location, although data were only collected on Fridays and Saturdays (Lacey et al., 2011).
} 


\section{Methodology}

The study was performed in Catalonia (Spain), a Mediterranean region with a population that exceeded 7.5 million inhabitants in 2012. The population of interest comprises all drivers that circulate on the main interurban roads of Catalonia. Given that it is clearly infeasible to perform breath alcohol tests on the entire driving population, it is necessary to devise a mechanism to ensure that the sample of tested drivers is both random and representative. Breath alcohol testing checkpoints were randomly allocated and BrAC tests were performed on drivers at all the checkpoints, with the objective of obtaining an accurate estimate of the overall alcohol-impaired driving rate in Catalonia. The team of traffic agents that conducted the tests followed standard procedures, and no exceptions were permitted in the way the checkpoints and modus operandi were established. Only the personal information about each driver as shown on the driving license (that is, age, gender, nationality and the validity of the license) was collected. The number of occupants in the vehicle and the type of vehicle were also recorded, together with the result in $\mathrm{mg} / \mathrm{l}$ of the BrAC test. When a result above the legal limit was obtained, a second confirmatory test was conducted, following standard procedures ${ }^{5}$. The time and location were recorded.

\subsection{Territorial scope}

For operational purposes, the traffic authorities divide Catalonia into eight Regional Traffic Areas (RTAs hereafter). Roads are classified in two groups, namely, high speed roads and conventional roads. Each road is divided in sections, where a section is defined as a fraction of a road that includes no major intersection. The length of these sections is not homogeneous throughout the territory. Some sections can be several kilometers long (the case of certain highways), whereas others (in certain country areas) might be quite short. Table 1 shows the number of sections and the percentage of sections that correspond to high speed roads (highways or motorways) and conventional roads.

\footnotetext{
${ }^{5} \mathrm{~A}$ preliminary alcohol breath test is conducted in the driver's automobile using a portable breathalyzer. This test outcome has no legal validity. If a positive result above the legal limit is obtained, then the $\mathrm{BrAC}$ is tested in the traffic agent's automobile using an evidential breath testing device. When the specimen of breath gives a result above the legal limit, a second confirmatory breath test is performed after half an hour. The lower of these results is retained as evidence.
} 
Table 1. Distribution of road sections within the Regional Traffic Areas of Catalonia, Spain (2012) by type of road

\begin{tabular}{lcccc}
\hline \multicolumn{1}{c}{ Regional Traffic Area (RTA) } & $\begin{array}{c}\text { Number of } \\
\text { sections }\end{array}$ & $\begin{array}{c}\text { High speed* } \\
(\%)\end{array}$ & $\begin{array}{c}\text { Conventional } \\
(\%)\end{array}$ & TOTAL \\
\hline Girona & 1,241 & $17 \%$ & $83 \%$ & $100 \%$ \\
Metropolitana Nord & 895 & $36 \%$ & $64 \%$ & $100 \%$ \\
Metropolitana Sud & 571 & $32 \%$ & $68 \%$ & $100 \%$ \\
Camp de Tarragona & 1,008 & $17 \%$ & $83 \%$ & $100 \%$ \\
Terres de l'Ebre & 384 & $4 \%$ & $96 \%$ & $100 \%$ \\
Ponent & 817 & $12 \%$ & $88 \%$ & $100 \%$ \\
Central & 970 & $21 \%$ & $79 \%$ & $100 \%$ \\
Pirineu Occidental & 351 & $0 \%$ & $100 \%$ & $100 \%$ \\
\hline TOTAL & 6,237 & $19 \%$ & $81 \%$ & $100 \%$ \\
\hline * High-speed roads include highways and motorways. All other roads are referred to as being \\
conventional.
\end{tabular}

The flow of vehicles on a road is not homogeneous during the day (Garber and Hoel, 2009; Roess et al., 2011), it being estimated that only around one per cent of daily vehicles use the road per hour in the time-frames of low vehicle flow (Cal and Cardenas, 1998; Pasaoglu et al., 2012). The information on average daily traffic (ADT) is gathered annually by the local traffic authority. Low-intensity roads were not included in the sample design so as to ensure a minimum number of vehicles during the time that the sobriety checkpoint was operational. According to the traffic authorities it takes an average of five minutes to conduct a breath test. Roads with an average intensity of traffic below 4,000 vehicles per day, i.e. 40 vehicles per hour in the timeframe of low flow, were not included in the sample. Although the literature suggests that there is a tendency in alcohol-impaired drivers to use such roads in order to avoid sobriety checkpoints (Vanlaar, 2008), the inclusion of low-intensity roads would have required an unrealistic number of testing teams. The number of road sections in Catalonia that present an average daily traffic intensity of more than 4,000 vehicles per day is 3,135 .

\subsection{Time scope}

The sample was conducted in the spring of 2012. Alcohol-impaired driving in Catalonia may follow a seasonal pattern with impaired-driving patterns being motivated by seasonal variations in alcohol consumption in the population (Del Río et al., 2002). According to statistical series from the Catalan Traffic Authority, non-random alcohol tests performed in Catalonia in the period 2007-2012 show lower positive rates in winter than in summer. As spring is associated with intermediate rates it was chosen as the data collection period for random alcohol tests. Non-random BrAC tests 
performed in autumn also show positive rates between the winter and summer bounds, and in general lower rates than in spring ${ }^{6}$.

The current sample is a cross-section based on the data gathered during a two-month period. Random breath alcohol testing controls were performed in three time intervals of: 16 - 26 April 2012, 3 - 24 May 2012, and 30 May - 11 June 2012. There were no bank holidays, other than ordinary Sundays, in these three periods and so there are no special features that might have influenced the usual flow and intensity of vehicles in the transport network or the driving pattern of the population. The sample design intentionally did not include days with atypical traffic flows (such as holidays), as they could potentially distort the results.

\subsection{Sample selection}

The sample seeks to be representative of all drivers that circulate on the main interurban roads of Catalonia. Given the nature of the study, a two-stage sampling procedure was carried out to gather the data. The first stage was designed to select the road sections and which therefore constitute our primary sample units (PSUs). The second stage was aimed at selecting the drivers to be tested, who constitute therefore our secondary sample units (SSUs).

The road sections selected (PSUs) serve as the basis for generating the spatial dimension, i.e. where the police BrAC testing checkpoints are located. These PSUs were selected using stratified sampling. The stratification variables were: geographical area (RTA), road type (high-speed or conventional), flow direction, day of week and time-slot (six four-hour intervals). The first stratification criterion was based on the geographical area and road type. The road sections were selected so as to provide a proportional representation of the RTAs and road types across the territory. The flow direction was chosen randomly with respect to the road kilometer counter, with half the PSUs being located in the rising direction (assumed to be the one in which cars moved in the same direction as the increase in road kilometers) and half in the decreasing direction.

Selecting road sections on which to locate the sobriety checkpoints was a further issue that had to be resolved in the sample design. A road section can be considered to constitute that part of the road lying between a given access and exit. In each stratum sections were selected based on a probability that was proportional to size (i.e., the length of the section). The selection mechanism ensured that the probability of a particular road section being chosen was proportional to its length in meters. Sampling

\footnotetext{
${ }^{6} \mathrm{~A}$ second wave of random BrAC tests was launched in autumn, as indicated in the Annex.
} 
was performed with replacement, meaning that any road section could be chosen more than once. However, we imposed a limit so that any one road section could not be selected more than three times. For each road section, safe areas for locating the sobriety checkpoint were recommended by the traffic agents. On high-speed roads, for security reasons, checkpoints had to be located at accesses or exits. However, on other types of road, the traffic agents were free to choose where to locate the checkpoint within each section.

Once the road sections and flow directions had been selected, they were equidistributed across days of the week and the time-slots for all the RTAs, with each road section being randomly matched to a day of the week and time-slot. The time schedules (day and hour) were chosen as homogenously as possible with respect to drivers' alcohol consumption behavior so as to avoid any biases. The time-slots considered were ${ }^{7}:$ 2:00 - 6:00 hrs, 6:00 - 10:00 hrs, 10:00 - 14:00 hrs, 14:00 - 18:00 $\mathrm{hrs}, 18: 00-22: 00 \mathrm{hrs}$ and 22:00 - 2:00 hrs. The days of the week were also randomly allocated. Thus, the PSUs were designed to be representative of the road network in Catalonia and, moreover, of the road networks within each of the eight RTAs. This first stage constitutes a stratified non-proportional sample and as such weights are required to ensure the correct representation of the global network.

A list of the checkpoints selected was given to the authority police officer responsible for each RTA. Each designation included the road section, flow direction, day of week and time-slot for conducting the BrAC test. Any unexpected difficulty preventing the tests being performed as defined by this schedule required the authorization of the sample design group who provided a substitute location (as similar as possible to the original) at which the tests would be conducted on the previously established day of the week and within the same time interval ${ }^{8}$.

The second stage in the sample design involved the selection of the individual drivers to be tested. Once the checkpoint had been set up by the traffic agents at the place, day and time indicated, the drivers required to perform the BrAC tests were randomly chosen by the officers. In other words, drivers were chosen using a simple random sampling method as they approached the checkpoint. In fact, the traffic officers stopped the first vehicle to approach the sobriety roadblock once they were ready to perform the test. It should be borne in mind that the goal is to measure the rate of

\footnotetext{
${ }^{7}$ Time-slots were designed to coincide with the working hours of the traffic agents.

${ }^{8}$ Once the locations of all the sobriety checkpoints had been selected, an alternative location that could be used as a substitute was provided in case it was not possible to set up the checkpoint due to unforeseen circumstances, such as road works. Similarly, traffic officers were instructed to move to this alternative location if they were obliged to close their roadblock more than $\mathbf{3 0}$ minutes before schedule (for instance, agents had to attend an accident or other emergency situation). The alternative control points were identical to the original ones in terms of the stratification variables.
} 
alcohol-impaired driving in Catalonia as accurately as possible. Here, checkpoints were not intentionally sited to fulfill preventive objectives, as is often the traffic authority's criterion. And, so, the vehicles were not selected on the basis of any observable characteristic or a priori suspicion of the probability of detecting a positive outcome. The random-selection feature makes the dataset a very powerful tool for making precise estimations of the alcohol-impaired driving rate.

\subsection{Weight estimates}

Given that we opted to restrict the sample to roads with a medium-high ADT, an immediate consequence of imposing this restriction is that conventional roads are underrepresented. This is one of the reasons why our statistical analysis requires sample weights and the assumption that excluding conventional road sections with low intensity does not bias the results. Specifically, we used the estimated ADT for each road section as a criterion for constructing the weight of each observation. However, we only had access to one measure of traffic intensity on each road section, which did not allow us to take into account in the construction of the weights the fluctuations in traffic intensity over different time-slots and days of the week.

Each observation was assigned a weight. Weights were computed according to the following methodology. Let us assume the following notation. Superscript $v$ is used to denote the type of road (High speed road $v=1$ versus Conventional road $v=0$ ). Subscript $h$ is used to denote an administrative zone or stratum (RTA). There are eight zones so $h=1,2, \ldots, 8$. We denote by $N_{h}^{v}$ the number of road sections in zone $h$ of type $v$. We sample a fraction of these roads. The number of sections in the sample is denoted by $n_{h}^{v}$.

For every road section we have two magnitudes that characterize the section: its length in kilometers and the intensity of traffic measured as the estimated number of vehicles per day that use the section. We denote the section length by $l_{i h}^{v}$ for the $i$-th section of road type $v$ in zone $h, i=1, \ldots, N_{h}^{v}$. We denote the section intensity of traffic by $d_{i h}^{v}$ for the $i$-th section of road type $v$ in zone $h, i=1, \ldots, N_{h}^{v}$. A section is relatively more important for us than another section if its traffic intensity is higher or its length is greater. So, we compute relative length and relative intensity as, $\frac{l_{i h}^{v}}{\sum_{j=1}^{N_{h}^{v}} l_{j h}^{v}}$ and $\frac{d_{i h}^{v}}{\sum_{j=1}^{N_{h}^{v}} d_{j h}^{v}}$, respectively. 
Once $n_{h}^{v}$ sections are sampled proportional to length in each zone and type of road, we need to calculate the total traffic intensity that is represented by these sections. Therefore we compute $\sum_{j=1}^{N_{h}^{v}} d_{j h}^{v}$, which is the sum of intensities in the population in zone $h$ type $v$, and compare to $\sum_{j=1}^{n_{h}^{v}} d_{j h}^{v}$, which is the sum of intensities in the sampled subgroup of road sections. The ratio between these two is the relative sampled intensity and we can denote this by $r_{h}^{v}$. We have $k$ breath alcohol tests in section $i$, and denote by $t_{i h}^{v}$ the duration of the sobriety roadblock in this section, while $m_{i h}^{v}$ denotes the total number of BrAC tests performed during the roadblock.

So, the (non-scaled) weight for every test $k=1, \ldots, m_{i h}^{v}$ is called $w_{k i h}^{v}, i=1, \ldots, n_{h}^{v}$, $w_{k i h}^{v}=d_{i h}^{v} r_{h}^{v} t_{i h}^{v}\left(m_{i h}^{v}\right)^{-1} h_{m i h}^{v} S_{h}^{v}$, where $h_{\text {mih }}^{v}$ depends on the time interval attending to the heterogeneous distribution of traffic throughout the day. The factor $h_{\operatorname{mih}}^{v}$ seeks to capture the differences in the flow of vehicles from one time interval to another. The reason we include this factor is because we know that traffic intensity diminishes substantially during the night. Taking into account what we know about car trip distribution by time of the day in Europe (Pasaoglu et al., 2012), we approximate $h_{m i h}^{v}$ to 0.12 if the alcohol tests are performed between 22:00 and 2:00 hrs, to 0.08 if tests are performed between 2:00 and 6:00 hrs, and to 0.20 for each one of the remaining four-hour periods between 6:00 and 22:00 hrs. These time-frames divide the day into time-slots within which the flow of vehicles is nearly homogeneous. Factor $s_{h}^{v}$ represents the size of type of road $v$ in zone $h$ relative to the other zones. Note that the geographical extension of zones and their location with respect to the metropolitan area is very diverse. So we have calculated a relative size of a zone as $s_{h}^{v}=\left(\sum_{j=1}^{N_{h}^{v}} d_{j h}^{v} / N_{h}^{v}\right) \sum_{j=1}^{N_{h}^{v}} l_{j h}^{v}$. Finally, weights are proportionally scaled so that the sum of weights is equal to the total number of BrAC tests performed. The weights associated with each RTA range from an average of 0.0315 in a low traffic density RTA to 0.2683 in the immediate outskirts of the urban area of Barcelona.

\subsection{Sample size and estimated sampling error}

This study forms part of a research program promoted by the Catalan Traffic Authority. In this case, a total of 720 hours of BrAC testing was conducted across Catalonia, corresponding to the total resources allocated by the traffic authority to the study. Our target was to obtain 90 hours of test results for each RTA. The traffic authorities in 
each RTA were allowed to conduct the operation in one of two ways: either 60 checkpoints of 90 minutes duration each or 90 checkpoints of 60 minutes duration each. Most of the RTA authorities opted for the second option, with the exception of the RTAs of Metropolitana Sud and Ponent. Thus, checkpoints were sited at a total of 660 different locations (Figure 1).

Figure 1. Distribution of breath alcohol testing checkpoints in Catalonia by Regional Traffic Areas (Spring 2012)

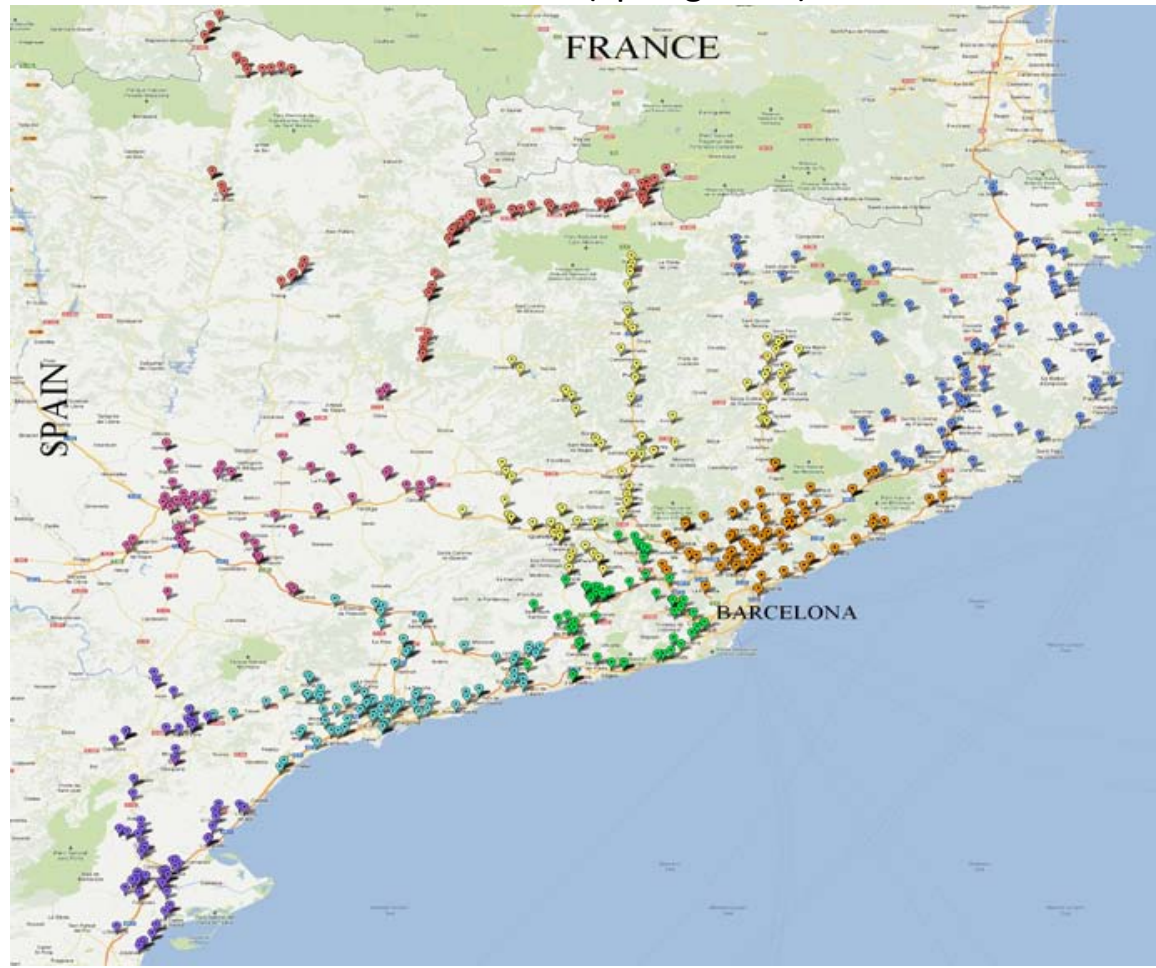

Note: Girona RTA (dark blue tick); Metropolitana Nord RTA (orange tick); Metropolitana Sud RTA (green tick); Camp de Tarragona RTA (light blue tick); Terres de l'Ebre RTA (lilac tick); Ponent RTA (pink tick); Central RTA (yellow tick); Pirineu Occidental RTA (red tick).

Error margins can be constructed based on statistical sampling analysis (Kish, 1995; Levy, 1991). If we consider that previous studies carried out in Catalonia by the Catalan Traffic Authority seldom showed an alcohol-impaired driving rate greater than $2 \%$ (Annex), we can conclude that the estimation for Catalonia as a whole has a maximum error margin of $\pm 0.3 \%$, whilst the estimations for the RTAs have an error of $\pm 1.0 \%$ at most. Both estimated sampling errors are calculated at the $95 \%$ confidence level and we assume a similar number of tests was performed in the previous study conducted in 2010 (in which a total of 7,351 tests were made). Under these assumptions it can be asserted that the sample is statistically representative of Catalonia's driving population. 


\section{Results}

The number and the duration of sobriety checkpoints per RTA (recall low-intensity roads were excluded) was large enough to obtain a final sample size of 7,596 $\mathrm{BrAC}$ rate tests, distributed across the eight RTAs of Catalonia. Due to the sample design, each test observation has an associated weight according to the representativeness criteria described in section 3 . All the results reported in this section therefore take the sample design into consideration by means of associated weights, since failure to do so would introduce biased outcomes. The estimated percentage values of positive outcomes from random BrAC tests per RTA are shown in Table 2. The percentage of positive outcomes for the whole driving population of Catalonia was $1.29 \%$. This result is compared with the percentage of positive outcomes obtained from non-random BrAC tests, i.e. when tests were performed in sobriety checkpoints strategically located with the aim of preventing road accidents ${ }^{9}$. The rate of positive outcomes from nonrandom BrAC tests in spring 2012 was 4.38\%. As expected, the percentage of BrAC level outcomes above the legal limit is much lower when the tests were conducted at randomly located sobriety checkpoints.

Table 2. Rates of positive outcomes per RTA from random BrAC tests (Spring 2012)*

Regional Traffic Area (RTA)

Positive rate

Confidence interval (95\%)

\begin{tabular}{lll}
\hline Girona & $2.49 \%$ & $(1.52 \% ; 3.46 \%)$ \\
Metropolitana Nord & $1.39 \%$ & $(0.65 \% ; 2.13 \%)$ \\
Metropolitana Sud & $0.94 \%$ & $(0.31 \% ; 1.57 \%)$ \\
Camp de Tarragona & $1.46 \%$ & $(0.75 \% ; 2.17 \%)$ \\
Terres de l'Ebre & $0.34 \%$ & $(0.00 \% ; 0.70 \%)$ \\
Ponent & $1.31 \%$ & $(0.50 \% ; 2.13 \%)$ \\
Central & $0.26 \%$ & $(0.00 \% ; 0.60 \%)$ \\
Pirineu Occidental & $1.09 \%$ & $(0.46 \% ; 1.73 \%)$ \\
\hline Total & $1.29 \%$ & $(1.04 \% ; 1.54 \%)$ \\
\hline
\end{tabular}

* Note: The rate of positive outcomes from non-random BrAC tests for the whole driving population in Catalonia was $4.38 \%$ in spring 2012.

For the sake of brevity, hereafter we focus solely on aggregate results for the whole of Catalonia and not those reported for each of the RTAs. In doing so we lose very little generality given that the RTAs were constructed by the traffic authorities for purely

\footnotetext{
${ }^{9}$ The non-random BrAC test results were obtained from specifically located sobriety checkpoints. Data from non-random BrAC tests performed on drivers involved in an accident or suspected by traffic officers of driving under the effects of alcohol were not included.
} 
organizational purposes. Moreover, most of the RTAs exhibit similar patterns to those of the aggregate.

Table 3 summarizes the main results from the BrAC tests that were performed in this study. It is important to note that the Spanish legislation ${ }^{10}$ distinguishes between two types of offense: administrative-positives and criminal-positives. The former are drivers with a BrAC level between 0.25 and $0.60 \mathrm{mg} / \mathrm{l}$ and who face an administrative sanction. Drivers with a BrAC level above $0.60 \mathrm{mg} / \mathrm{l}$ are considered to have committed a criminal offense and face more severe legal sanctions, such as fines, temporary suspension of driving license and incarceration. For the purpose of this study, we do not differentiate between these two types of positives.

Table 3. Adjusted results of random BrAC tests in Catalonia (Spain) per road type, day of week and time-slot in spring 2012

\begin{tabular}{llcccc}
\hline & & $\begin{array}{c}\text { Number of } \\
\text { tests }\end{array}$ & $\begin{array}{c}\text { Number of } \\
\text { positives }\end{array}$ & $\begin{array}{c}\text { Number of } \\
\text { negatives }\end{array}$ & $\begin{array}{c}\text { \% positive } \\
\text { tests }\end{array}$ \\
\hline Road type & $\begin{array}{l}\text { Conventional } \\
\text { High-speed }\end{array}$ & $3,144.50$ & 31.39 & $3,113.11$ & 1.00 \\
& $4,451.50$ & 66.51 & $4,384.99$ & 1.49 \\
& Monday & $1,082.00$ & 5.93 & $1,076.08$ & 0.55 \\
Day of the & Tues-Thurs & $3,016.76$ & 10.37 & $3,006.38$ & 0.34 \\
week & Friday & $1,107.36$ & 6.67 & $1,100.69$ & 0.60 \\
& Saturday & $1,112.87$ & 21.12 & $1,091.75$ & 1.90 \\
& Sunday & $1,277.02$ & 53.82 & $1,223.19$ & 4.21 \\
& & & & & \\
Time-slot & $14-22 \mathrm{hrs}$ & $2,659.20$ & 35.82 & $2,623.39$ & 1.35 \\
& 22-06 hrs & $2,015.43$ & 28.23 & $1,987.20$ & 1.40 \\
\hline Total & & $7,596.00$ & 97.91 & $7,498.09$ & 1.29 \\
\hline
\end{tabular}

As shown in Table 3, high-speed roads exhibit a higher percentage of positive tests $(1.49 \%)$ than those shown on conventional roads (1.00\%). This is of particular concern given that the probability of experiencing severe injuries or death in a road accident increases with speed (O'Donnell and Connor, 1996; Kockelman and Kweon, 2002). Moreover, it is widely known that higher speeds and alcohol consumption both have a positive marginal effect on the probability of being involved in an accident (Elvik, 2005). Thus, the combination of these two factors can be expected to have a positive effect (possibly synergistic) on this probability. However, the fact that high-speed

\footnotetext{
${ }^{10}$ Spanish legislation on alcohol-impaired driving is contained in Chapter 4 of the Government Decree 1428/2003 (Real Decreto 1428/2003), and Article 379 of the Spanish Criminal Code (Código Penal).
} 
roads have wider lanes and hard shoulders than those found on conventional roads, and the traffic flows are separated by a central reservation, may have a compensating effect (Rifaat and Chin, 2007). Hence, the overall effect is ambiguous and the policy implication of this result is therefore unclear.

The distribution of the percentage of positives across the days of the week is unsurprising. Consistent with the results in the literature (Vanlaar, 2005), weekdays present a much lower rate than weekends. Sunday is the day with the single highest rate (4.21\%). Predictably, the rate peaks between 06:00 and 10:00 am (6.19\%) on Sundays, a time interval which matches perfectly with the closing time of clubs and discotheques, which are especially crowded on Saturday nights. The rate of prevalence declines steadily for the remaining two time-slots of the day. Finally, it is worth noting that the rate is higher during the night $(1.40 \%)$ than during the daytime. Although the data are not shown, this pattern is particularly marked for Saturdays and Sundays and is less intense for weekdays.

\subsection{The distribution of BrAC levels}

Traffic officers recorded the BrAC level for each driver tested, regardless of whether they exceeded the legal limit or not, so we are able to characterize the distribution of the BrAC levels for negative and positive tests separately. While as many as $94.86 \%$ of drivers presented a $\mathrm{BrAC}$ rate of $0.00 \mathrm{mg} / \mathrm{l}, 3.85 \%$ presented a positive reading within the legal limits, with the remaining $1.29 \%$ exceeding the limit. This implies that conditional on having a BrAC level above zero, the number of negatives is still significantly higher than the number of positives.

Moreover, if we restrict our attention to drivers who while testing negative presented a BrAC level above zero, we see that $88.02 \%$ of these cases (3.47\% of the aggregate) presented a rate below $0.16 \mathrm{mg} / \mathrm{l}$. In other words, most had a $\mathrm{BrAC}$ level well below the legal limit $(0.25 \mathrm{mg} / \mathrm{l})$. As can be seen in Figure 2 , the distribution increases over a short range and, after, it is strictly decreasing in the BrAC level, as only $3.20 \%$ of these cases had a BrAC level near the legal boundary. 
Figure 2. Empirical distribution of $\mathrm{BrAC}$ level of drivers conditional on their having a BrAC level above zero

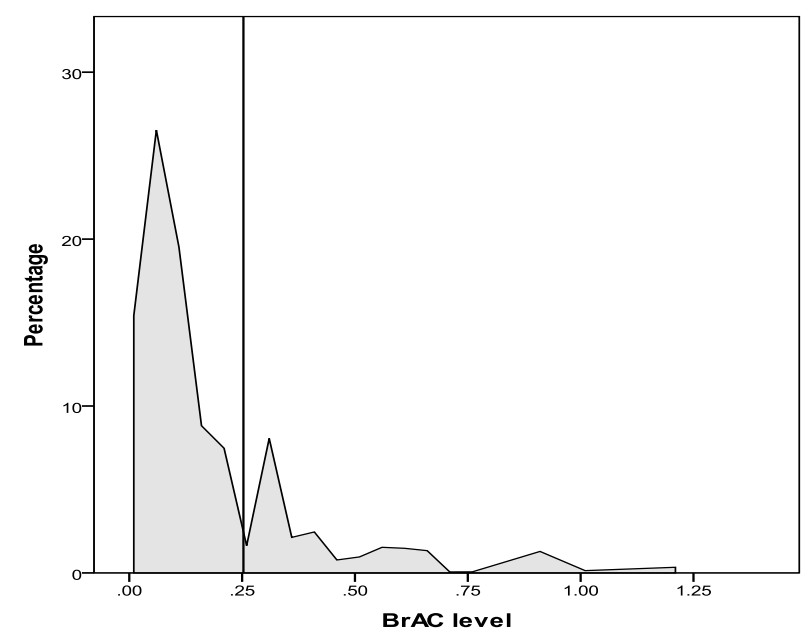

If we focus our attention on the distribution of the BrAC level of those drivers that tested positive - namely, those who exhibited a BrAC level above the general legal limit of $0.25 \mathrm{mg} / \mathrm{l}$ (or $0.15 \mathrm{mg} / \mathrm{l}$ for particular groups of drivers such as professional drivers or inexperienced drivers), in contrast with what was observed for the negatives, the distribution of positive values is not decreasing in the BrAC level (Figure 3). We observe that the distribution of positive tests peaks at $0.31 \mathrm{mg} / \mathrm{l}$ and slowly decreases thereafter, albeit not continuously. Indeed, two local peaks are recorded at around 0.65 and $0.90 \mathrm{mg} / \mathrm{l}$. More than $50 \%$ of the positives have a BrAC level above $0.40 \mathrm{mg} / \mathrm{l}$, which is significantly higher than the legal limit. Moreover, $22.15 \%$ of these cases exhibited a BrAC level above $0.60 \mathrm{mg} / \mathrm{l}$; i.e. above the criminal limit.

Figure 3. Adjusted distribution of $\mathrm{BrAC}$ level of drivers conditional on their having a BrAC level above the legal limit

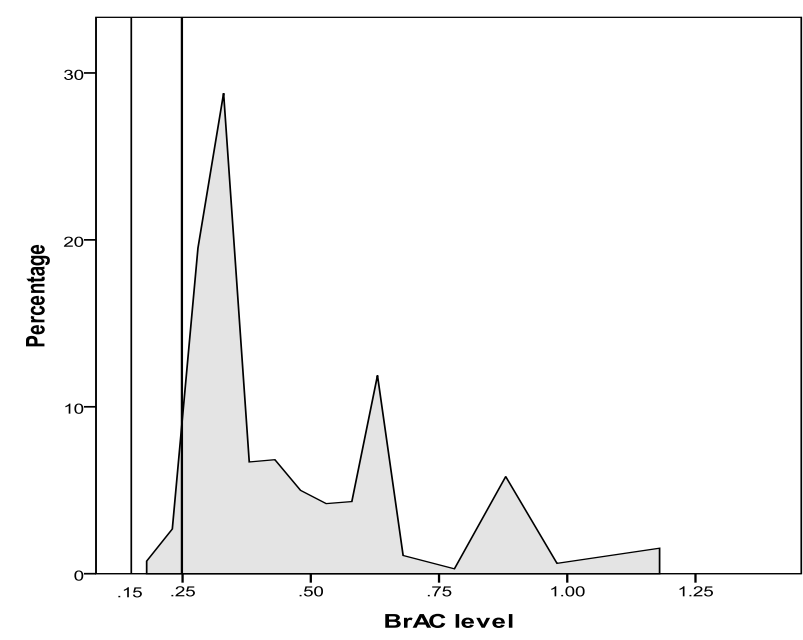


Therefore, two different patterns can be identified among drivers that had consumed alcoholic beverages. One seems to represent the cautious behavior manifest by the negatives with non-zero BrAC levels, which appears to be absent among the positives. In other words, the fact that the distribution for the negatives is so positively skewed suggests that in most of these cases drivers consciously seek to refrain from approaching the legal limit boundary. However, the fact that the distribution for the positive outcomes slowly decreases - albeit with peaks - across different BrAC levels reveals what is an apparently less careful behavior towards respecting the legal limit. Because of these two opposite patterns of drinking behavior manifested by drivers, only a small number of cases are near the legal boundary.

\subsection{Other factors}

The driver's personal characteristics, in addition to information related to the type of vehicle being driven and the number of occupants in the vehicle, were collected by the traffic officer. The results of the random BrAC tests by gender and age of the driver, the number of occupants in the vehicle, as well as vehicle type, are shown in Table 4.

Table 4. Results of random BrAC tests in Catalonia (Spain) by type of driver and vehicle in spring 2012

\begin{tabular}{llrrrr}
\hline & \multicolumn{1}{c}{$\begin{array}{c}\text { Number of } \\
\text { tests }\end{array}$} & $\begin{array}{c}\text { Number of } \\
\text { positives }\end{array}$ & $\begin{array}{c}\text { Number of } \\
\text { negatives }\end{array}$ & $\begin{array}{c}\text { \% positive } \\
\text { tests }\end{array}$ \\
\hline Gender & Men & $6,115.83$ & 88.42 & $6,027.41$ & 1.45 \\
& Women & $1,480,17$ & 9.49 & $1,470.68$ & 0.64 \\
& & & & & \\
& 18 & 1.13 & 0.00 & 1.13 & 0.00 \\
Age & $18-24$ & 837.68 & 7.37 & 830.32 & 0.88 \\
& $25-34$ & $1,873.53$ & 23.50 & $1,850.02$ & 1.25 \\
& $35-44$ & $2,538.05$ & 22.66 & $2,515.39$ & 0.89 \\
& $45-54$ & $1,427.57$ & 23.20 & $1,404.36$ & 1.63 \\
& $55-64$ & 669.12 & 16.99 & 652.13 & 2.54 \\
& $65-74$ & 183.61 & 3.16 & 180.45 & 1.72 \\
Type of & $<75$ & 65.31 & 1.03 & 64.28 & 1.58 \\
vehicle* & & & & & \\
& Light & $7,087.41$ & 95.52 & $6,991.89$ & 1.35 \\
& Heavy & 311.37 & 2.39 & 308.98 & 0.77 \\
& Two-wheels & 146.77 & 0.00 & 146.77 & 0.00 \\
& Others & 50.45 & 0.00 & 50.45 & 0.00 \\
Number of & & & & & \\
occupants & 1 & $4,311.82$ & 36.39 & $4,275.43$ & 0.84 \\
& 2 & $2,098.15$ & 54.89 & $2,043.26$ & 2.62 \\
& 3 & 716.15 & 6.14 & 710.01 & 0.86 \\
& 4 & 332.02 & 0.32 & 331.71 & 0.10 \\
& $>4$ & 137.85 & 0.17 & 137.68 & 0.12 \\
\hline
\end{tabular}

* Light vehicles refer to cars and vans. Heavy vehicles consist of lorries, trucks and buses. Two-wheels refers to motorbikes and motorcycles. Finally, the category Others includes all other vehicles, such as agricultural vehicles, terrain cranes, etc. 
A clear finding is that ceteris paribus men are more likely to engage in drink driving than women. As shown in Table 4, the proportion of men with a BrAC level above the legal limit $(1.45 \%)$ is almost three times that of women $(0.64 \%)$. This result is consistent with the literature (Institoris et al., 2005; Woratanarat et al., 2009; Bergen et al., 2011; Kelley-Baker et al., 2013; Kim et al., 2013). Yet, it should be noted that around $80 \%$ of the tested drivers were men, which means that male drivers are much more frequent than female drivers on non-urban roads in Catalonia. As such, policies targeting male awareness of the dangers of drink driving, if effective, would have a great impact on the alcohol level of the driving population.

If we examine the percentage of positive tests across the age groups, we find that drivers aged between 55 and 64 are the group presenting the highest rates (2.54\%). This result was unexpected as most of the previous literature reports a decreasing rate with age, with drivers under 25 being the highest risk group (Mathijssen, 2005; Bergen et al., 2011; Kelley-Baker et al., 2013). If we bear in mind that these studies are based on non-random BrAC tests taken at checkpoints sited near night clubs and discotheques, typically frequented by young people, our results make sense. Outside certain specific time frames and beyond certain BrAC checkpoint sites, young drivers are not the highest risk group. Although a strictly monotonic relationship is not observed, it would appear that in our population, the percentage of positives tends to increase with age until 64 years and to decrease thereafter.

Vehicle type seems to be a relevant category for explaining drink-driving behaviour. For instance, we did not record a single positive case for drivers of two-wheeled vehicles. This result might be due to the fact that motorbikes are infrequent users of roads in non-urban areas, as only 147 drivers of two-wheeled vehicles were tested in this study. Alternatively, it might be the case that such drivers are aware of the importance of abstaining from alcohol due to their greater vulnerability in case of accident or that they exercise greater caution with respect to drink-driving because riding a motorbike requires greater coordination and balance (Sun et al., 1998). Conversely, the drivers of light vehicles presented a much higher percentage of positive tests $(1.35 \%)$ than drivers of heavy vehicles $(0.77 \%)$. The fact that more drivers of heavy vehicles work as professional drivers could explain this difference ${ }^{11}$.

Finally, vehicles with two occupants are found to present the highest percentage of positive tests $(2.62 \%)$. This percentage of positive outcomes practically triples that of vehicles with a different number of occupants. This result is of some interest, as to the best of our knowledge it has never before been reported in the literature. The role of an accompanying passenger is unclear. A priori it is expected that an accompanying

\footnotetext{
${ }^{11}$ The legal limit for professional drivers is 0.15 milligrams of alcohol in a liter of breath. Positive BrAC outcomes receive a sanction that includes a minimum three-month suspension of the driving license.
} 
person would deter an individual that has been drinking from driving. However, the higher percentage reported here might be connected to the socialization of drinking habits. Note that on Saturdays and Sundays there were on average 1.88 and 2.11 occupants per vehicle respectively, compared with just 1.63 occupants per vehicle on Mondays. A further plausible explanation might be the perceived sense of security provided by the presence of a second occupant. However, a higher percentage of positive outcomes is not observed when there are more than two occupants in the vehicle. A possible explanation for this fall in positive outcomes could be that vehicles with more than two occupants tend to be family groups (parents and children) and so drivers of such vehicles would be more aware of the dangers of driving drunk. Another reason may be related to the small number of sample cases with more than two occupants, especially vehicles carrying four or more occupants. Further research is required on this matter, but it lies beyond the scope of the present study.

To conclude, given the nature of our sample, we can attest to the validity of our findings for the period in which the data were collected (spring 2002). However, we cannot assume that the results are valid for other periods of the year. Additional information gathered in random controls in other time periods would help to evaluate the evolution in the alcohol-impaired driving rate in Catalonia over time. For this purpose, estimates of the alcohol-impaired driving rate from three previous studies carried out by the Catalan Traffic Authority are provided in the Annex. It clearly shows that the percentage of alcohol-impaired drivers in Catalonia has fallen steadily over the last few years. Moreover, the reduction has increased year-on-year which gives us a very sharp decrease if we consider the entire period (2007-2012). More specifically, the magnitude of the estimate has fallen by $56.4 \%$ in just five years.

\section{Conclusions}

Random breath alcohol tests were performed on a large representative sample of drivers in Catalonia (Spain) during the spring of 2012. One of the main strengths of our study is the validity of the data guaranteed by the methodology employed in the data gathering process. Thus, the sample is large and representative of drivers circulating on the non-urban roads of the region. The data were gathered at random checkpoints, which were located using a careful stratification methodology. This is a crucial distinction, given that the percentage of positives obtained was roughly a third of the total obtained when using data gathered at non-random checkpoints. After an exhaustive analysis of the data, our point estimate of the rate of alcohol-impaired drivers in Catalonia is $1.29 \%$ for the spring of 2012 . Yet, it should be noted that the percentage of positive tests in the same period at non-random, preventive checkpoints in Catalonia was $4.38 \%$. This clearly reflects the fact that (strategic) traffic controls 
suffer a large selection bias and cannot be considered representative of the driving population. This distortion occurs because the sites for the preventive checkpoints are specifically selected so as to maximize the number of detections per vehicle tested and to alert drivers of the risk of driving drunk, as opposed to simply measuring the percentage of positive outcomes.

We examined the factors influencing the probability of an individual driving under the effects of alcohol. As expected, the percentage of positives is significantly higher on Saturdays and Sundays than on weekdays. Specifically, Sunday is the day on which the rate peaks. Similarly, the rate is higher during the night than during the day. This pattern is accentuated on weekends. Thus, weekend nights are the time of the week at which the rate is highest. During the early hours of Sunday, the peak is almost four times higher than the mean. Consistent with reports in the literature, the rate of positives is significantly higher for men than for women. However, contrary to our expectations, young people do not constitute a particularly high-risk group. In fact, the percentage of positives shows an increasing though not strictly monotonic pattern for age.

Vehicles with two occupants exhibit a much higher percentage of positives than vehicles with a different number of occupants. Finally, drivers on high-speed roads show a significantly higher percentage of positives than drivers on conventional roads. However, we need to treat this last assertion with some caution, given that our sample excluded low average daily traffic (ADT) roads and, so, many conventional roads were excluded after we imposed this restriction. Experience tells us that alcohol-impaired drivers are inclined to use this kind of road in order to avoid alcohol testing checkpoints and this tendency could be accentuated during weekends.

Compared to the outcomes reported in previous studies, the overall rate identified here has undergone a sharp reduction. The preventive campaigns mounted by the regional government have been intensified in recent years and our results suggest that these actions have been effective, in combination with the heightened presence of traffic authorities on the roads conducting sobriety tests. Attempts at increasing public awareness of the dangers of drink driving are not exclusive to Spain. Similar media campaigns have been launched by virtually all governments around the world. In most countries, the authorities have increased drink driving penalties and lowered legal blood alcohol content levels in their efforts to reduce the number of traffic accidents attributable to alcohol. Our results seem to indicate that setting up checkpoints to test breath alcohol concentrations acts as a deterrent for drunk driving, because drivers are strongly influenced by the consequences of being tested positive. 
We should emphasize that one of the limitations of this study is that we would have benefitted from more accurate information for creating the weights to attach to each observation. The potential for improving the constructions of these weights exists however as more accurate information becomes available from the pertinent institutions.

\section{Acknowledgments}

The authors thank the Spanish Ministry of Education and the ERDF for grants ECO201221787-C01-03 and ECO2012-35584. We also thank the Catalan Traffic Authority, the Catalan police force Mossos d'Esquadra and GESOP for carrying out the field work and providing the data. M. Guillén also wishes to express her gratitude to ICREA Academia. 


\section{Annex}

We provide estimates of the alcohol-impaired driving rate from three previous studies carried out by the Catalan Traffic Authority, with data from 2007, 2009 and 2010. However, various factors must be taken into account. In the first place, the weights used in each of these three studies differ from those used for the current 2012 edition. More specifically, the earlier studies used different weights for each day of the week and did not distinguish by time-slots. In order to make valid comparisons, the data from these previous studies were reweighted according to the weights used in the present edition. Moreover, we need to bear in mind that our estimates are sensitive to seasonal differences. For the present edition, data for both the spring and the autumn were gathered. The wave carried out in the autumn consisted of a sample of 2,240 random BrAC tests. Our estimate for the yearly average BrAC level (2012) was constructed by taking a weighted average of the aforementioned figures (Table A.1).

For the previous three editions, however, the data were gathered solely during the autumn. Based on the study conducted in 2012, we learnt that the proportion of positive outcomes in random BrAC tests is higher during the spring than during the autumn. Additionally, the positive results in non-random BrAC tests presented seasonal patterns during the period analyzed, as indicated in section 3.2. Therefore, the raw estimates from the previous three editions are expected to be negatively biased if the seasonal component is not taken into consideration. Before comparing the figures a seasonal adjustment was performed for the years 2007, 2009 and 2010. Given that traffic officers regularly record the BrAC levels of the tests they perform at non-random checkpoints, a time series analysis allows us to retrieve the seasonal component for each month in the year. This is what we used as a baseline to adjust the estimated rates of positive outcomes at random checkpoints from each of the previous years contained in Table A.1.

Table A.1. Evolution in seasonally adjusted BrAC positive outcomes in Catalonia (Spain) over the period 2007-2012

\begin{tabular}{ccccc}
\hline Year & $\begin{array}{c}\text { Original } \\
\text { estimate } \\
\text { (autumn) }\end{array}$ & $\begin{array}{c}\text { Adjusted } \\
\text { estimate } \\
\text { (year) }\end{array}$ & $\begin{array}{c}\text { Interannual } \\
\text { variation }\end{array}$ & $\begin{array}{c}\mathbf{2 0 0 7 - 2 0 1 2} \\
\text { variation }\end{array}$ \\
\hline 2007 & $2.30 \%$ & $2.43 \%$ & - & - \\
2009 & $2.06 \%$ & $2.18 \%$ & $-10.3 \%$ & - \\
2010 & $1.57 \%$ & $1.66 \%$ & $-23.9 \%$ & - \\
2012 & $0.69 \%$ & $1.06 \%$ & $-36.1 \%$ & $-56.4 \%$ \\
\hline
\end{tabular}




\section{References}

Ahlm, K., Björnstig, U., Öström, M., 2009. Alcohol and drugs in fatally and non-fatally injured motor vehicle drivers in northern Sweden. Accident Analysis and Prevention, 41(1), 129-136.

Bergen, G., Shults, R.A., Rudd, R.A., 2011. Vital signs: Alcohol-impaired driving among adults - United States, 2010. Morbidity and Mortality Weekly Report, 60(39), 13511356.

Cal, R., Cárdenas, J., 1998. Ingeniería de Tránsito. Fundamentos y aplicaciones. México: Alfaomega.

Campos, V.R., De Souza e Silva, R., Dualibi, S., Laranjeira, R., Palacios, E.N., Grube L.W., Pinsky, I., 2013. Drinking and driving in southeastern Brazil: Results from a roadside survey study. Addictive Behaviors, 38(1), 1442-1447.

Chongsuvivatwong, V., Ritsmitchai, S., Suriyawongpaisal, P., Chariyalertsak, S., Weerachai, K., Punyaratabandhu, P., Sutiwipakorn, W., V. I. R. A. S. A. K. D. I., 1999. High prevalence of drink-driving in Thailand. Drug and Alcohol Review, 18(3), 293-298.

Del Río, M.C., Prada, C., Alvarez, F.J., 2002. Drinking habits throughout the seasons of the year in the Spanish population. Journal of Studies on Alcohol, 63(5), 577-580.

Downey, L.A., King, R., Papafotiou, K., Swann, P., Ogden, E., Boorman, M., Stough, C., 2013. The effects of cannabis and alcohol on simulated driving: Influences of dose and experience. Accident Analysis and Prevention, 50, 879-886.

Elvik, R., 2005. Speed and road safety: synthesis of evidence from evaluation studies. Transportation Research Record: Journal of the Transportation Research Board, 1908(1), 59-69.

Garber, N.J., Hoel, L.A., 2009. Traffic and Highway Engineering. Toronto: Cencage Learning.

Gjerde, H., Normann, P.T., Pettersen, B.S., Assum, T., Aldrin, M., Johansen, U., Kristoffersen, L., Øiestad, E.L., Christophersen, A.S., Mørland, J., 2008. Prevalence of alcohol and drugs among Norwegian motor vehicle drivers: a roadside survey. Accident Analysis and Prevention, 40(5), 1765-1772. 
Holmgren, P., Holmgren, A., Ahlner, J., 2005. Alcohol and drugs in drivers fatally injured in traffic accidents in Sweden during the years 2000-2002. Forensic Science International, 151, 11-17.

Institoris, L., Tóth, A.R., Molnár, A., Árok, Z., Kereszty, É., Varga, T., 2013. The frequency of alcohol, illicit and licit drug consumption in the general driving population in South-East Hungary. Forensic Science International, 224(1-3), 37-43.

Kelley-Baker, T., Lacey, J.H., Voas, R.B., Romano, E., Yao, J., Berning, A., 2013. Drinking and Driving in the United States: Comparing Results from the 2007 and 1996 National Roadside Surveys. Traffic Injury Prevention, 14(2), 117-126.

Kim, J.H., Wong, A.H., Goggings, W.B., Lau, J., Griffiths, S.M., 2013. Drink driving in Hong Kong: The competing effects of random breath testing and alcohol tax reductions. Addiction, 108(7), 1217-1228.

Kish, L., 1995. Survey Sampling. New York: Wiley.

Kockelman, K.M., Kweon Y.J., 2002. Driver injury severity: an application of ordered probit models. Accident Analysis and Prevention, 34(3), 313-321.

Lacey, J.H., Kelley-Baker, T., Voas, R.B., Romano, E., Furr-Holden, C.D., Torres. P., Berning, A., 2011. Alcohol- and Drug-Involved Driving in the United States: Methodology for the 2007 National Roadside Survey. Evaluation Review, 35(4), 319353.

Levy, P.S., 1991. Sampling of populations: Methods and applications. New York: John Wiley \& Sons.

Löbmann, R., 2002. Drunk driving: probability of detection and its perception. Policing: An International Journal of Police Strategies \& Management, 25(4), $770-788$.

Mathijssen, M.P.M., 2005. Drink driving policy and road safety in the Netherlands: a retrospective analysis. Transportation Research Part E, 41(5), 395-408.

Moskowitz, H., Fiorentino, D., 2000. A review of the literature on the effects of low doses of alcohol on driving-related skills. Report No. DOT HS 809 028. National Highway Traffic Safety Administration, Washington.

O'Donnell, C.J., Connor, D.H., 1996. Predicting the severity of motor vehicle accident injuries using models of ordered multiple choice. Accident Analysis and Prevention, 28(6), 739-753. 
Pasaoglu, G., Fiorello, D., Martino, A., Scarcella, G., Alemanno, A., Zubaryeva, A., Thiel, C., 2012. Driving and parking patterns of European car drivers: a mobility survey. JRC Scientific and Policy Reports, European Commission.

Peek-Asa, C., 1999. The effect of random alcohol screening in reducing motor vehicle crash injuries. American Journal of Preventive Medicine, 16(1), supl., 57-67.

Peek-Asa, C., Kraus. J.F., 1996. Alcohol use, driver, and crash characteristics among injured motorcycle drivers. The Journal of Trauma and Acute Care Surgery, 41 (6), 989993.

Rifaat, S.M., Chin, H.C., 2007. Accident severity analysis using ordered probit model. Journal of Advanced Transportation, 41(1), 91-114.

Roess, R.P., Prassas, E.S., McShane, W.R., 2011. Traffic Engineering. New Jersey: Prentice Hall.

Sun, S. W., Kahn, D. M., Swan, K. G., 1998. Lowering the legal blood alcohol level for motorcyclists. Accident Analysis and Prevention, 30(1), 133-136.

Vanlaar, W., 2005. Drink driving in Belgium: results from the third and improved roadside survey. Accident Analysis and Prevention, 37(3), 391-397.

Vanlaar, W., 2008. Less is more: The influence of traffic count on drinking and driving behaviour. Accident Analysis and Prevention 40(3), 1018-1022.

Vanlaar, W., Robertson, R., Marcoux, K., Mayhew, D., Brown, S., \& Boase, P., 2012. Trends in alcohol-impaired driving in Canada. Accident Analysis and Prevention, 48(SI), 297-302.

Voas, R.B., Johnson, M.B., Miller, B.A., 2013. Alcohol and drug use among young adults driving to a drinking location. Drug and Alcohol Dependence, in press.

Wagenaar, A.C., Zobeck, T., Williams, G.D., Hingson, R., 1995. Methods used in studies of drink-drive control efforts: a meta-analysis of the literature from 1960 to 1991. Accident Analysis and Prevention, 27(3), 307-316.

WHO, 2011. Global status report on alcohol and health. World Health Organization, Geneva.

Williams, A.F., 2006. Alcohol-impaired driving and its consequences in the United States: The past 25 years. Journal of Safety Research, 37, 123-138. 
Woratanarat, P., Ingsathit, A., Suriyawongpaisal, P., Rattanasiri, S., Chatchaipun, P., Wattayakorn, K., Anukarahanonta, T., 2009. Alcohol, illicit and non-illicit psychoactive drug use and road traffic injury in Thailand: A case-control study. Accident Analysis and Prevention, 41(3), 651-657. 
Llista Document de Treball

\section{List Working Paper}

WP 2013/13 "Prevalence of alcohol-impaired drivers based on random breath tests in a roadside survey" Alcañiz, M.; Guillén, M.; Sánchez-Moscona, D.; Santolino, M.; Llatje, O. and Ramon, LI.

WP 2013/12 "When supply travels far beyond demand: Institutional and regulatory causes of oversupply in Spain's transport infrastructure" Albalate, D.; Bel, G. and Fageda, X.

WP 2013/11 "Indicators for the characterization of discrete Choquet integrals" Belles-Sampera, J.; Guillén, M.; Merigó, J.M. and Santolino, M.

WP 2013/10 "Broadband prices in the European Union: competition and commercial strategies" Calzada, J. and Costas, A.

WP 2013/09 "Broadband prices in the European Union: competition and commercial strategies" Calzada, J. and Martínez, F.

WP 2013/08 "Double Penalty in Returns to Education: Informality and Educational Mismatch in the Colombian Labour market" Herrera-Idárraga, P.; López-Bazo, E. and Motellón, E.

WP 2013/07 "Firm exports, innovation, ... and regions" López-Bazo, E. and Motellón, E.

WP 2013/06 "Fiscal sustainability and fiscal shocks in a dollarized and oil-exporting country: Ecuador" Marí Del Cristo, L.M. and Gómez-Puig, M.

WP 2013/05 "Informality and Overeducation in the Labor Market of a Developing Country" HerreraIdárraga, P.; López-Bazo, E. and Motellón, E.

WP 2013/04 "GLS based unit root tests for bounded processes" Carrion-i-Silvestre, J.LI. and Gadea, M.D.

WP 2013/03 "Determinants of Broadband Access: Is Platform Competition always the Key Variable to Success?" Fageda, X.; Rubio, R. and Termes, M.

WP 2013/02 "Beyond Value-at-Risk: GlueVaR Distortion Risk Measures" Belles-Sampera, J.; Guillén, M. and Santolino, M.

WP 2013/01 "How systemic is Spain for Europe?" Claeys, P. and Vašícek, B.

WP 2012/24 "Changes in Wage Structure in Mexico Going Beyond the Mean: An Analysis of Differences in Distribution, 1987-2008" Tello, C.; Ramos, R, and Artís, M.

WP 2012/23 "Decomposing the Rural-Urban Differential in Student Achievement in Colombia Using PISA Microdata" Ramos, R.; Duque, J.C. and Nieto, S.

WP 2012/22 "Recovery Risk and Labor Costs in Public-Private-Partnerships: Contractual Choice in the U.S. Water industry" Albalate, D, Bel, G. and Geddes, R.

WP 2012/21 "Beyond pure public and pure private management models: Mixed firms in the European Airport Industry" Albalate, D.; Bel, G. and Fageda, X.

WP 2012/20 "The determinants of contractual choice for private involvement in infrastructure projects in the United States" Albalate, D, Bel, G. and Geddes, R.

WP 2012/19 "Measuring Sovereign Bond Spillover in Europe and the Impact of Rating News" Claeys, P. and Vašíček, B.

WP 2012/18 "Entry Regulation Asymmetries and Gasoline Competition in a Mixed Motorway Network" Albalate, D. and Perdiguero, J. 
WP 2012/17 "Regulation of Port Charges in Spain: Global versus Local Competition" Fageda, X. and Gonzalez-Aregall, M.

WP 2012/16 "Pass-through in dollarized countries: should Ecuador abandon the U.S. Dollar?" Marí del Cristo, M.L. and Gómez-Puig, M.

WP 2012/15 "A Note on the Relationship Between the Cyclicality of Markups and Fiscal Policy" Claeys, P. and Costa, L.F.

WP 2012/14 "Do intra- and inter-industry spillovers matter? CDM model estimates for Spain" Goya, E.; Vayá, E and Suriñach, J.

WP 2012/13 "What Drives the Choice of Partners in R\&D Cooperation? Heterogeneity across Sectors" Badillo, E. and Moreno, R.

WP 2012/12 "Corruption and local politics: does it pay to be a crook?" Jiménez, J.L. and García, C.

WP 2012/11 "Not always sunny in paradise: prices and brand diversity in touristic areas supermarkets" Campos, J.; Jiménez, J.L. and Suárez-Alemán, A.

WP 2012/10 "The institutional, economic and social determinants of local government transparency" Albalate, D.

WP 2012/09 "The business excellence attraction composite index (BEACl). Design and apllication to the municipalities of the Barcelona province" Murillo, J.; Romaní, J.; Suriñach, J.

WP 2012/08 "Policy options for the promotion of electric vehicles: a review" Perdiguero, J. and Jiménez, J.L.

WP 2012/07 "Price differences between domestic and international air markets: an empirical application to routes from Gran Canaria" Fageda, X.; Jiménez, J.L. and Díaz Santamaría, C.

WP 2012/06 "Building a "quality in work" index in Spain" López-Tamayo, J.; Royuela, V. and Suriñach, J.

WP 2012/05 "Mergers and difference-in-difference estimator: why firms do not increase prices?" Jiménez, J.L. and Perdiguero, J.

WP 2012/04 "What attracts knowledge workers? The role of space, social connections, institutions, jobs and amenities" Miguélez, E. and Moreno, R.

WP 2012/03 "What Drives the Urban Wage Premium? Evidence along the Wage Distribution" Matano, A. and Naticchioni, $P$.

WP 2012/02 "Location Patterns of Creative Capital and Regional Disparities in Spain" Kerimoglu, E. and Karahasan, B.C.

WP 2012/01 "The connection between distortion risk measures and ordered weighted averaging operators" Belles-Sampera, J.; Merigó, J.M.; Guillén, M. and Santolino, M.

WP 2011/26 "Productivity and innovation spillovers: Micro evidence from Spain" Goya, E.; Vayá, E. and Suriñach, J.

WP 2011/25 "The regional distribution of unemployment. What do micro-data tell us?" López-Bazo, E. and Motellón, E.

WP 2011/24 "Vertical relations and local competition: an empirical approach" Perdiguero, J.

WP 2011/23 "Air services on thin routes: Regional versus low-cost airlines" Fageda, X. and Flores-Fillol, R.

WP 2011/22 "Measuring early childhood health: a composite index comparing Colombian departments" Osorio, A.M.; Bolancé, C. and Alcañiz, M.

WP 2011/21 "A relational approach to the geography of innovation: a typology of regions" Moreno, R. and Miguélez, E. 
WP 2011/20 "Does Rigidity of Prices Hide Collusion?" Jiménez, J.L and Perdiguero, J.

WP 2011/19 "Factors affecting hospital admission and recovery stay duration of in-patient motor victims in Spain" Santolino, M.; Bolancé, C. and Alcañiz, M.

WP 2011/18 "Why do municipalities cooperate to provide local public services? An empirical analysis" Bel, G.; Fageda, X. and Mur, M.

WP 2011/17 "The "farthest" need the best. Human capital composition and development-specific economic growth" Manca, F.

WP 2011/16 "Causality and contagion in peripheral EMU public debt markets: a dynamic approach" Gómez-Puig, M. and Sosvilla-Rivero, S.

WP 2011/15 "The influence of decision-maker effort and case complexity on appealed rulings subject to multi-categorical selection" Santolino, M. and Söderberg, M.

WP 2011/14 “Agglomeration, Inequality and Economic Growth” Castells, D. and Royuela, V.

WP 2011/13 "A correlation sensitivity analysis of non-life underwriting risk in solvency capital requirement estimation" Bermúdez, L.; Ferri, A. and Guillén, M.

WP 2011/12 "Assessing agglomeration economies in a spatial framework with endogenous regressors" Artis, M.J.; Miguélez, E. and Moreno, R.

WP 2011/11 "Privatization, cooperation and costs of solid waste services in small towns" Bel, G; Fageda, $\mathrm{X}$. and Mur, M.

WP 2011/10 "Privatization and PPPS in transportation infrastructure: Network effects of increasing user fees" Albalate, D. and Bel, G.

WP 2011/09 "Debating as a classroom tool for adapting learning outcomes to the European higher education area" Jiménez, J.L.; Perdiguero, J. and Suárez, A.

WP 2011/08 "Influence of the claimant's behavioural features on motor compensation outcomes" Ayuso, M; Bermúdez L. and Santolino, M.

WP 2011/07 "Geography of talent and regional differences in Spain" Karahasan, B.C. and Kerimoglu E.

WP 2011/06 "How Important to a City Are Tourists and Daytrippers? The Economic Impact of Tourism on The City of Barcelona" Murillo, J; Vayá, E; Romaní, J. and Suriñach, J.

WP 2011/05 "Singling out individual inventors from patent data" Miguélez,E. and Gómez-Miguélez, I.

WP 2011/04 “¿La sobreeducación de los padres afecta al rendimiento académico de sus hijos?” Nieto, S; Ramos, R.

WP 2011/03 “The Transatlantic Productivity Gap: Is R\&D the Main Culprit?” Ortega-Argilés, R.; Piva, M.; and Vivarelli, M.

WP 2011/02 "The Spatial Distribution of Human Capital: Can It Really Be Explained by Regional Differences in Market Access?" Karahasan, B.C. and López-Bazo, E

WP 2011/01 "I If you want me to stay, pay" . Claeys, P and Martire, F

WP 2010/16 "Infrastructure and nation building: The regulation and financing of network transportation infrastructures in Spain (1720-2010)"Bel,G

WP 2010/15 "Fiscal policy and economic stability: does PIGS stand for Procyclicality In Government Spending?" Maravalle, A ; Claeys, P.

WP 2010/14 "Economic and social convergence in Colombia" Royuela, V; Adolfo García, G.

WP 2010/13 "Symmetric or asymmetric gasoline prices? A meta-analysis approach" Perdiguero, J.

WP 2010/12 “Ownership, Incentives and Hospitals” Fageda,X and Fiz, E. 
WP 2010/11 "Prediction of the economic cost of individual long-term care in the Spanish population" Bolancé, C; Alemany, R ; and Guillén M

WP 2010/10 "On the Dynamics of Exports and FDI: The Spanish Internationalization Process" MartínezMartín J.

WP 2010/09 "Urban transport governance reform in Barcelona” Albalate, D ; Bel, G and Calzada, J.

WP 2010/08 "Cómo (no) adaptar una asignatura al EEES: Lecciones desde la experiencia comparada en España" Florido C. ; Jiménez JL. and Perdiguero J.

WP 2010/07 "Price rivalry in airline markets: A study of a successful strategy of a network carrier against a low-cost carrier" Fageda, X ; Jiménez J.L. ; Perdiguero , J.

WP 2010/06 "La reforma de la contratación en el mercado de trabajo: entre la flexibilidad y la seguridad" Royuela V. and Manuel Sanchis M.

WP 2010/05 "Discrete distributions when modeling the disability severity score of motor victims" Boucher, J and Santolino, M

WP 2010/04 "Does privatization spur regulation? Evidence from the regulatory reform of European airports . Bel, G. and Fageda, X."

WP 2010/03 "High-Speed Rail: Lessons for Policy Makers from Experiences Abroad". Albalate, D ; and Bel, G."

WP 2010/02 "Speed limit laws in America: Economics, politics and geography". Albalate, D ; and Bel, G."

WP 2010/01 "Research Networks and Inventors' Mobility as Drivers of Innovation: Evidence from Europe" Miguélez, E. ; Moreno, R."

WP 2009/26 "Social Preferences and Transport Policy: The case of US speed limits" Albalate, D.

WP 2009/25 "Human Capital Spillovers Productivity and Regional Convergence in Spain", Ramos, R ; Artis, M.; Suriñach, J.

WP 2009/24 "Human Capital and Regional Wage Gaps",López-Bazo,E. Motellón E.

WP 2009/23 "Is Private Production of Public Services Cheaper than Public Production? A metaregression analysis of solid waste and water services" Bel, G.; Fageda, X.; Warner. M.E.

WP 2009/22 "Institutional Determinants of Military Spending" Bel, G., Elias-Moreno, F.

WP 2009/21 "Fiscal Regime Shifts in Portugal” Afonso, A., Claeys, P., Sousa, R.M.

WP 2009/20 "Health care utilization among immigrants and native-born populations in 11 European countries. Results from the Survey of Health, Ageing and Retirement in Europe" Solé-Auró, A., Guillén, M., Crimmins, E.M.

WP 2009/19 "La efectividad de las políticas activas de mercado de trabajo para luchar contra el paro. La experiencia de Cataluña" Ramos, R., Suriñach, J., Artís, M.

WP 2009/18 "Is the Wage Curve Formal or Informal? Evidence for Colombia" Ramos, R., Duque, J.C., Suriñach, J.

WP 2009/17 "General Equilibrium Long-Run Determinants for Spanish FDI: A Spatial Panel Data Approach" Martínez-Martín, J.

WP 2009/16 "Scientists on the move: tracing scientists' mobility and its spatial distribution" Miguélez, E.; Moreno, R.; Suriñach, J. 
WP 2009/15 "The First Privatization Policy in a Democracy: Selling State-Owned Enterprises in 19481950 Puerto Rico" Bel, G.

WP 2009/14 “Appropriate IPRs, Human Capital Composition and Economic Growth” Manca, F.

WP 2009/13 "Human Capital Composition and Economic Growth at a Regional Level" Manca, F.

WP 2009/12 "Technology Catching-up and the Role of Institutions" Manca, F.

WP 2009/11 "A missing spatial link in institutional quality" Claeys, P.; Manca, F.

WP 2009/10 "Tourism and Exports as a means of Growth" Cortés-Jiménez, I.; Pulina, M.; Riera i Prunera, C.; Artís, M.

WP 2009/09 "Evidence on the role of ownership structure on firms' innovative performance" OrtegaArgilés, R.; Moreno, R.

WP 2009/08 ¿¿Por qué se privatizan servicios en los municipios (pequeños)? Evidencia empírica sobre residuos sólidos y agua" Bel, G.; Fageda, X.; Mur, M.

WP 2009/07 "Empirical analysis of solid management waste costs: Some evidence from Galicia, Spain" Bel, G.; Fageda, X.

WP 2009/06 “Intercontinental fligths from European Airports: Towards hub concentration or not?” Bel, G.; Fageda, $\mathrm{X}$.

WP 2009/05 "Factors explaining urban transport systems in large European cities: A cross-sectional approach" Albalate, D.; Bel, G.

WP 2009/04 "Regional economic growth and human capital: the role of overeducation" Ramos, R.; Suriñach, J.; Artís, M.

WP 2009/03 "Regional heterogeneity in wage distributions. Evidence from Spain" Motellón, E.; LópezBazo, E.; El-Attar, M.

WP 2009/02 "Modelling the disability severity score in motor insurance claims: an application to the Spanish case" Santolino, M.; Boucher, J.P.

WP 2009/01 "Quality in work and aggregate productivity" Royuela, V.; Suriñach, J.

WP 2008/16 "Intermunicipal cooperation and privatization of solid waste services among small municipalities in Spain" Bel, G.; Mur, M.

WP 2008/15 "Similar problems, different solutions: Comparing refuse collection in the Netherlands and Spain" Bel, G.; Dijkgraaf, E.; Fageda, X.; Gradus, R.

WP 2008/14 "Determinants of the decision to appeal against motor bodily injury settlements awarded by Spanish trial courts" Santolino, M

WP 2008/13 "Does social capital reinforce technological inputs in the creation of knowledge? Evidence from the Spanish regions" Miguélez, E.; Moreno, R.; Artís, M.

WP 2008/12 "Testing the FTPL across government tiers" Claeys, P.; Ramos, R.; Suriñach, J.

WP 2008/11 "Internet Banking in Europe: a comparative analysis" Arnaboldi, F.; Claeys, P.

WP 2008/10 "Fiscal policy and interest rates: the role of financial and economic integration" Claeys, P.; Moreno, R.; Suriñach, J.

WP 2008/09 "Health of Immigrants in European countries" Solé-Auró, A.; M.Crimmins, E.

WP 2008/08 "The Role of Firm Size in Training Provision Decisions: evidence from Spain” Castany, L.

WP 2008/07 "Forecasting the maximum compensation offer in the automobile BI claims negotiation process" Ayuso, M.; Santolino, M. 
WP 2008/06 "Prediction of individual automobile RBNS claim reserves in the context of Solvency II" Ayuso, M.; Santolino, M.

WP 2008/05 "Panel Data Stochastic Convergence Analysis of the Mexican Regions" Carrion-i-Silvestre, J.L.; German-Soto, V.

WP 2008/04 "Local privatization, intermunicipal cooperation, transaction costs and political interests: Evidence from Spain" Bel, G.; Fageda, X.

WP 2008/03 "Choosing hybrid organizations for local services delivery: An empirical analysis of partial privatization" Bel, G.; Fageda, X.

WP 2008/02 "Motorways, tolls and road safety. Evidence from European Panel Data" Albalate, D.; Bel, G.

WP 2008/01 "Shaping urban traffic patterns through congestion charging: What factors drive success or failure?" Albalate, D.; Bel, G.

WP 2007/19 "La distribución regional de la temporalidad en España. Análisis de sus determinantes" Motellón, E.

WP 2007/18 "Regional returns to physical capital: are they conditioned by educational attainment?" López-Bazo, E.; Moreno, R.

WP 2007/17 "Does human capital stimulate investment in physical capital? evidence from a cost system framework" López-Bazo, E.; Moreno, R.

WP 2007/16 "Do innovation and human capital explain the productivity gap between small and large firms?" Castany, L.; López-Bazo, E.; Moreno, R.

WP 2007/15 "Estimating the effects of fiscal policy under the budget constraint" Claeys, P.

WP 2007/14 "Fiscal sustainability across government tiers: an assessment of soft budget constraints" Claeys, P.; Ramos, R.; Suriñach, J.

WP 2007/13 "The institutional vs. the academic definition of the quality of work life. What is the focus of the European Commission?" Royuela, V.; López-Tamayo, J.; Suriñach, J.

WP 2007/12 "Cambios en la distribución salarial en españa, 1995-2002. Efectos a través del tipo de contrato" Motellón, E.; López-Bazo, E.; El-Attar, M.

WP 2007/11 "EU-15 sovereign governments' cost of borrowing after seven years of monetary union" Gómez-Puig, M..

WP 2007/10 "Another Look at the Null of Stationary Real Exchange Rates: Panel Data with Structural Breaks and Cross-section Dependence" Syed A. Basher; Carrion-i-Silvestre, J.L.

WP 2007/09 "Multicointegration, polynomial cointegration and I(2) cointegration with structural breaks. An application to the sustainability of the US external deficit" Berenguer-Rico, V.; Carrion-iSilvestre, J.L.

WP 2007/08 "Has concentration evolved similarly in manufacturing and services? A sensitivity analysis" Ruiz-Valenzuela, J.; Moreno-Serrano, R.; Vaya-Valcarce, E.

WP 2007/07 "Defining housing market areas using commuting and migration algorithms. Catalonia (Spain) as an applied case study" Royuela, C.; Vargas, M.

WP 2007/06 "Regulating Concessions of Toll Motorways, An Empirical Study on Fixed vs. Variable Term Contracts" Albalate, D.; Bel, G.

WP 2007/05 "Decomposing differences in total factor productivity across firm size" Castany, L.; LopezBazo, E.; Moreno, R.

WP 2007/04 "Privatization and Regulation of Toll Motorways in Europe" Albalate, D.; Bel, G.; Fageda, X. 
WP 2007/03 "Is the influence of quality of life on urban growth non-stationary in space? A case study of Barcelona" Royuela, V.; Moreno, R.; Vayá, E.

WP 2007/02 "Sustainability of EU fiscal policies. A panel test" Claeys, P.

WP 2007/01 "Research networks and scientific production in Economics: The recent spanish experience" Duque, J.C.; Ramos, R.; Royuela, V.

WP 2006/10 "Term structure of interest rate. European financial integration" Fontanals-Albiol, H.; RuizDotras, E.; Bolancé-Losilla, C.

WP 2006/09 "Patrones de publicación internacional (ssci) de los autores afiliados a universidades españolas, en el ámbito económico-empresarial (1994-2004)" Suriñach, J.; Duque, J.C.; Royuela, V.

WP 2006/08 "Supervised regionalization methods: A survey" Duque, J.C.; Ramos, R.; Suriñach, J.

WP 2006/07 "Against the mainstream: nazi privatization in 1930s germany" Bel, G.

WP 2006/06 "Economía Urbana y Calidad de Vida. Una revisión del estado del conocimiento en España" Royuela, V.; Lambiri, D.; Biagi, B.

WP 2006/05 "Calculation of the variance in surveys of the economic climate" Alcañiz, M.; Costa, A.; Guillén, M.; Luna, C.; Rovira, C.

WP 2006/04 "Time-varying effects when analysing customer lifetime duration: application to the insurance market" Guillen, M.; Nielsen, J.P.; Scheike, T.; Perez-Marin, A.M.

WP 2006/03 "Lowering blood alcohol content levels to save lives the european experience" Albalate, D.

WP 2006/02 "An analysis of the determinants in economics and business publications by spanish universities between 1994 and 2004" Ramos, R.; Royuela, V.; Suriñach, J.

WP 2006/01 "Job losses, outsourcing and relocation: empirical evidence using microdata" Artís, M.; Ramos, R.; Suriñach, J. 


\section{$\mathbb{\Phi}|\mathrm{R}| \mathrm{E}|\mathrm{A}|$}

Institut de Recerca en Economia Aplicada Regional i Pública

Research Institute of Applied Economics

Universitat de Barcelona

Av. Diagonal, $690 \bullet 08034$ Barcelona

WEBSITE: www.ub.edu/irea/•CONTACT: irea@ub.edu 